\title{
UNIVERSITYOF
}

FORWARD

THINKING

WESTMINSTER用

WestminsterResearch

http://www.westminster.ac.uk/westminsterresearch

'She doesn't want to go to hospital. That's one thing she hates':

Collective performativity in avoidable nursing home to hospital

transfers

Makela, $\mathbf{P}$.

This is the peer reviewed version of the following article: Makela, P. (2018) 'She doesn't want to go to hospital. That's one thing she hates': Collective performativity in avoidable nursing home to hospital transfers, Journal of Evaluation in Clinical Practice, doi:

10.1111/jep.12985, which has been published in final form at

https://dx.doi.org/10.1111/jep.12985.

This article may be used for non-commercial purposes in accordance with Wiley Terms and Conditions for Self-Archiving.

The WestminsterResearch online digital archive at the University of Westminster aims to make the research output of the University available to a wider audience. Copyright and Moral Rights remain with the authors and/or copyright owners.

Whilst further distribution of specific materials from within this archive is forbidden, you may freely distribute the URL of WestminsterResearch: ((http://westminsterresearch.wmin.ac.uk/)).

In case of abuse or copyright appearing without permission e-mail repository@westminster.ac.uk 


\section{She doesn't want to go to hospital. That's one thing she hates': Collective performativity in avoidable nursing home to hospital transfers}

\section{Introduction}

A pattern of hospital discharge and readmission for older people, portrayed as a 'revolving door of emergency admission', has received increasing attention over recent decades [1]. A growing number of older people are living in nursing homes, many of whom will be nearing the end of life [2]. Nursing home residents are considered to be at high risk of being admitted to hospital in situations where this may have been avoided [3-5], though interpretations of hospitalisation as 'necessary' or 'avoidable' are complex and varied [6,7]. In the National Health Service (NHS) in England, avoidance of inappropriate hospital admission is a priority [8], when risks exceed potential health benefit $[9,10]$. More generally, the term 'overuse' has been used to refer to provision of services that are not likely to increase quality or quantity of life, or are experienced by people who would not have wanted the intervention if they had been fully aware of potential benefits and harms [11]. These preferences are varied and changeable, for example regarding care that prolongs life at the expense of comfort [12]. For the older individual, repeated experiences of physical assessments and transfers to hospital may lead to a sense of estrangement, or to viewing the body as an object over which they feel they have little control [13].

The number of beds in care homes (with and without nurses [1]) is approximately three times the number of beds in NHS hospitals in the United Kingdom [14]. National guidance from NHS England advocates avoidance of hospital transfers for residents 'where possible' [15]. However, professionals navigate a grey area in clinical decision making about sending a resident to hospital for medical treatment, in which they balance perceived risks and wellbeing with moral and ethical tensions [16]. Concern arises when courses of action are taken that may not be anticipated to change the course of illness or improve quality of life for the resident [17]. In addition, older people may experience harm when cared for in an acute hospital environment. Adverse factors proposed to contribute to morbidity include discontinuities in care and communication following transfer, suboptimal continence care and nutritional support [18], increased immobility and functional decline while admitted to a ward [19, 20], and high rates of in-hospital mortality [21].

Across the NHS, various initiatives have been developed that intend to address the national priority to avoid inappropriate hospitalisation for older people, while enabling timely clinical input and ensuring that nursing home residents are not inequitably disadvantaged [22]. The commissioning and organisation of nursing home-specific healthcare services is variable. Examples include the payment of incentives to general practitioners (GPs) to provide proactive visits, nursing home specialist nurses or support teams, pharmacist-led services, and the creation of specialist teams and outreach services led by hospital geriatricians $[14,23]$. 'Hospital avoidance programmes' aim to facilitate a more coordinated approach to recognising and managing change in nursing home residents' conditions, through strategies such as staff skills training, advance care planning, early warning tools based on physiological parameters, access to multidisciplinary teams, and provision of subacute care within the nursing home [3].

Variation exists in the use of available alternative services by nursing homes and in the nature and severity of conditions for which transfer from nursing home to hospital may be arranged [7, 24]. Nurses and nursing assistants provide the majority of care for nursing home residents and, as part of everyday interactions, will frequently be the staff who identify apparent deterioration or instability. 
Although decisions to admit nursing home residents to hospital often involve a broader healthcare team, these staff are central in the decision-making dilemma of whether to transfer a resident to an acute hospital or activate alternative responses [25]. Factors affecting staff actions in avoiding hospitalisation for nursing home residents are not well understood, with calls for greater understanding of drivers, how these may relate to the routine practices of facilities, and how individuals' own values and preferences may be integrated into decision making [24]. To date, there has been limited exploration of influences and drivers that result in service 'overuse' through inappropriate transfers of nursing home residents to acute hospitals [26].

\section{Aims and objectives}

The aim of this article is to explore the negotiation of nursing home residents' transfers to hospital, where they may have been avoidable. I propose that nursing homes represent sites of identify work for staff, residents and family members or other supporters. The term 'identity' refers to the meanings that individuals apply to themselves [27], which may be susceptible to many insecurities and result in identities which are precarious or uncertain [27]. 'Identity work' refers to the formation, preservation, repair and adjustment processes through which people pursue desired versions of themselves [28]. I use an application of Judith Butler's theory of performativity [28-30] to explore what else may be possible, when subjects view themselves to be at odds with the prevailing social norms in which they work or live. This Butler-informed approach seeks to disrupt and unsettle 'broad brushstroke' procedures and practices [31].

My focus is the healthcare system in England, as the context with which I have familiarity of the NHS in a role as a physician, and of a nursing home as a relative of a resident. This analysis has arisen through a critical curiosity: "a readiness to find what surrounds us as strange and odd; a readiness to throw off familiar ways of thought and to look at the same things in a different way" [32] p325. In acknowledging that there are no 'innocent positions' [33], I use situated perspectives from my own experiences of assessing people transferred into acute hospitals from nursing homes and also from interactions as a family member, concerning recurrent transfers of a nursing home resident to and from an acute hospital.

The article is structured as follows. Firstly, I consider conceptualisations of frailty and explore potential implications of its medicalisation in shaping cultures of paternalism and risk-aversion in nursing homes [34-36]. I contrast this discourse with the current ethicolegal drive for 'shared decision-making' and 'person-centred care', where people are supported to make informed decisions about their own care and choose when to invite others to act on their behalf $[37,38]$. In the second section, I draw on Butler's theory of performativity $[28,29]$ as a lens through which to consider identity work and behaviours in the institutional context of a nursing home, at the interface with the acute healthcare system. I consider understandings of agency for staff, residents and families, within a performative framing of the challenge presented by potentially avoidable transfers. I commence with an illustrative vignette:

A 95-year-old female arrives in Accident and Emergency. Earlier that afternoon, she had been sitting in the residents' lounge when nursing home staff carried out a routine set of physiological observations. They identified that she had lower-than-usual blood pressure and, following protocol, called the general practitioner (GP). The GP advised that she was unable to attend and asked nursing staff to call the ambulance service, who transferred Mrs $O$. to the 
local hospital. Accident and Emergency staff decide to admit her to an inpatient ward to allow time for assessment. They inform her next of kin of their plan [2].

\section{Medicalisation of frailty}

Medicalisation refers to "the process by which moral, social or legal problems become medical issues" [39] (p.8). The concept of medicalisation centres on the 'medical model' in which disease is assumed to have identifiable biological cause and action is orientated towards the intentions of curative medicine [17]. A long-standing sociological critique surrounds medicalisation as medical social control or the result of intentional expansion by the medical profession [40]. The concept has been considered to "trouble those who believe that we do best when we are left alone" [41] (p.323).

Medicalisation is apparent within clinical applications of the term 'frailty', used to describe decline in physiological reserve and function. A frequently used definition of frailty focusses on the evaluation of five domains: nutritional status, energy, physical activity, mobility and strength, intended to identify older people at increased of 'adverse outcomes' [42]. The term frailty is becoming established as a 'short-hand' that healthcare practitioners are increasingly expected to understand and apply within clinical decision making [43]. Medicalised conceptualisations of frailty are operationalised in practice through standardised frailty assessments. The British Geriatrics Society recommends that such assessments should be carried out 'at all encounters between health and social care staff and older people in community settings', using specified measures, questionnaires or checklists that capture clinical characteristics of frailty $[44,45]$.

Frailty, conceived as a complex health syndrome, attracts perceptions of risk of deterioration in trajectories that are considered unpredictable. Medicalisation therefore extends the context of healthcare intervention to areas of unspecified risk for those who are categorised as frail, specifying a state of vulnerability that provides foci for actions to be undertaken by others [46, 47]. Medicalisation of frailty overlooks "numerous opportunities to strengthen a person's overall health in his physical and social environments other than [through] disease-specific interventions" [48] p.205. Frailty as an identity is most often defined by these medicalised discourses, drawing upon objectification of impairment and physical deficit. It generates limited understanding or concern for the person's experience of being labelled 'frail', which older people may themselves resist or reject $[49,50]$.

The narrative surrounding the 'balance of power' between healthcare professionals and patients has shifted since original applications of the term 'medicalisation', acknowledging the implicit hierarchy of health professionals' status and social positioning [51]. A more recent and increasing rhetoric centres around involvement, choice, shared decision-making and enhancement of roles for recipients of services, families and other supporters [39]. However, older people may be particularly predisposed to a 'paternalistic' approach that is characterised by professional authority and a one-way communication style, where professionals inform patients about decisions they have made, in an asymmetric power balance [52].

\section{Norms, performativity and agency}

Medicalised norms and governing conventions of nursing home organisations seek standardisation in ways of being and acting for staff, residents and relatives or other visitors. Through compulsory repetitions, these conventions function as regulatory regimes that come to appear necessary. The goal may be to ensure a managed, 'risk-contained' environment, in which the normative measure relies 
upon standardisation of residents' lives and care [53]. Structures and staffing of nursing home organisations entail pressures on time available for tasks to be completed, and efficiency requirements may be addressed through standardised protocols. Nursing home conventions may compete with a focus on individuals' personal preferences and values [51] or may priortise the needs of the group of residents over the needs of particular individuals [36]. Staff may feel compelled to comply with protocol as they interpret it within a view of their professional obligations and their statutory duties to 'protect' residents [36,54], in addition to a need to maintain control of their own work [51].

\section{Performativity}

The theory of performativity is considered key within Judith Butler's work, seeking to disrupt categories that attempt to normalise, structure and regulate the ways people live [55]. Butler considers that identity categories may regulate individuals through an act of forming the subject to comply with rules of the dominant discourse. Subjectivity, encompassing an individual's sense of self, emotions and desires [56], becomes effected through reiterative performance that is compelled by governing practices of social coherence [29]. Although Butler originally addressed gender identity categories, I propose an application of the theory beyond gender, which may uncover spaces for agency and identity work. Through a performativity-inspired lens, I explore implications of structures and regulatory processes for nursing home residents[3], families and staff. The intention is not to transpose Butler's theories entirely, but to use this theoretical application to explore categorisations that appear necessary and may be controlling. For the purpose of this analysis, I focus predominantly on three propositions of the theory of performativity: citationality, interpellation and resignification.

\section{Citationality}

A key proposition of the theory of performativity is that of citationality, whereby ways of being are formed through citations, or repetitions, of past acts. Through citationality, structures, norms and conventions are reinforced and recreated as if afresh, time and again. This repetition is central to Butler's analysis, mediating between existing social norms and those who are performing them: the "repetition is not performed by the subject; this repetition is what enables a subject" [28] (p. 95). Performativity does not refer merely to a process of performance as a willed act but accounts for the constitution of a subject, through ways of being and doing that precede the subject $[28,30]$. Identity is produced as people repeat themselves, as an effect of normalised conventions [57]. Butler describes that the project of identity work plays a role in the preservation and repetition of coherent and consistent norms, through "the desire to persist in one's own social being" [58] (p. 44).

Organisational culture transmits power for ways of acting, shaping individuals' compliance with tacit regulations and conventions required by the hierarchy. Power can work through the association of materials and social processes, which create specific imaginaries that designate what may be deemed to be an 'appropriate' need or a 'required' course of action [59]. For staff members working together across organisational boundaries, tasks may be accomplished within an operative model or 'care pathway' that has become familiar among the team members, established and functionally set within structures, materials and processes.

Within healthcare systems and nursing homes, 'track and trigger' processes involve monitoring individuals' physiological parameters ('track') and determining when to 'trigger' a response, such as initiation of a medical assessment [60]. As illustrated in the opening vignette, vital signs can represent quantifiable indicators that a person 'is deteriorating', which nursing home staff use to package the communication of an assessment when seeking escalation of care [61, 62]. Staff then relay 
information about their concerns over possible clinical deterioration, by speaking "in codified ways" [30] p.148. Butler draws attention to Austin's emphasis on 'perlocution' or speech-acts that are effective only under certain circumstances that permit the particular effect [30]. Here, performative communications (or practices) bring into being that of which they speak: a deterioration that will require medical attention.

\section{Interpellation}

Interpellation, originally described by Althusser [63]), refers to the 'hailing' of individuals as subjects by dominant ideologies (e.g. of a family, of a nursing home, of the healthcare service), constituting the nature of identities within social interactions. Butler considers that interpellation seeks to "introduce a reality rather than report on an existing one" [64] p.33, by indicating a subject position in a social space that has become possible through the citation of existing conventions. Everyday rituals subject individuals to dominant ideologies, producing subjectivities through social forces rather than through individuals' willed acts as independent agents. Individuals recognising themselves as the one who is 'hailed' then act in the conventionally expected manner and the subject position becomes established through reiterations over time.

Professionals who work closely with individuals may consider themselves to act as 'facilitators and advisors' for older people [17] yet relative positions of power may diminish residents' sense of self, leading to the adoption of a passive stance within interactions [65]. The concept of 'social death' has emphasised "the cessation of the individual person as an active agent in others' lives" [66] (p.178) and may confront residents living in nursing homes, if standardised routines of tasks are 'done to' them and are experienced as depersonalising [67]. For the resident, these practices and interactions with staff do not simply address care needs, but become world forming. Family members may find themselves 'on the outside, looking in' when previous conventions of family interrelations become disrupted by the daily routines of the nursing home. Their potential contributions may go unrecognised, or may not be integrated with care by healthcare staff, if their actions are instead shaped by interpellation as 'visitors' within the social space of the nursing home.

Families are frequently called upon as default proxy decision-makers, if a relative is deemed to 'lack capacity' to make an informed, decision-specific choice according to principles of the Mental Capacity Act (England and Wales) [68]. 'Best interests' discussions are intended to take into account past and present wishes, values and beliefs of the individual [69]. Accounts from families may convey previously expressed views, as illustrated by one relative: "She doesn't want to go to hospital. That's one thing she hates doing" [17] (p.3). However, families may withhold such assertions during 'best interests' discussions, and the degree to which families are able to play a determinative role in transfer decisions has been questioned [70]. The application of informed consent is itself open to debate, potentially representing a citational practice as "a formulaic stand-in for ethical dialogue and deliberation" [71] p.27.

Interpellation as a resident or visitor brings an understanding that someone else is making decisions and may mean that, if a staff convey a decision about hospital transfer, then that outcome becomes inevitable. At times of decision making and planning, families may be unable disrupt professionals' nuanced ways of applying unspoken and often invisible 'rules of the game' [72]. Qualitative research has documented ways that "residents did little more than obey nurses' orders, comply with their requests, and accept care that did not always meet their needs" [73] p.159. Individuals may even 'appear unconcerned' about this, feeling part of a bigger process, or that is necessary to relinquish control to 'the system', thereby representingperformative acquiescence [74]. Interpellation operates particularly when people believe that the values invoked are their own or that they reflect the most 
obvious and logical way to act. Operation of power may then become "masked by its production of willing subjects" in residents and their family members [75].

\section{Agency as resignification}

Gilleard and Higgs propose that frailty infers evacuation of agency [46], where agency can be understood as "the ability to act independently and to influence the outside world or others, or to resist interventions by others" [67] (p.5). Implementation of the performative lens allows alternative understandings of agency. Butler portrays agency not as an intentional, independent response, but coming from reconfiguring of responses and conventions through a project of 'self-crafting' that is always at work in "...negotiating an answer to the question of who the ' $I$ ' will be in relation to norms [of the situation]" [58] (p.22). Following Butler's theory, reiterative performative acts can both reproduce and challenge normative identity categories. Iterability of everyday routines opens up other possibilities that are also performative practices, bringing the potential for production of difference, while remaining bound to the constraints of power relations that produce them. Discourses and power relations make intelligible social categories, which provide a recognisable and enduring social existence constituted through performative acts, yet subjectivity is not wholly determined or fixed. Agency is produced by the possibilities of reconfiguring the self (as a personal awareness of a continuity of being [76]), through formations that are not fully constrained in advance. Space exists for transforming and reworking one's established way of being, in which agency then represents a 'resignification' of processes and responses [28].

When considering nursing homes, subjectivities of staff, residents and families are shaped through effects of power as they assume their positions within the dominant discourse. Extending this view, the power of preceding conventions creates subjects through dependence and interrelations [77]. Influences in relationships between residents and those caring for them become key in a relational conception of agency [35], bringing intersubjective responsibility for attention to "those unique things that make me, me" [78](p.1). Subjectivities may also be conflicted, for example if a staff member identifies a risk and escalates medical referral or hospital transfer but is aware that the action may threaten the fulfilment of previously stated wishes.

For staff working within established conventions, opportunities for agency arise during those grey areas of decision making, and can become apparent if "we risk ourselves in those moments of unclarity, where that which conditions us and that which lies within us diverge from each other" [79]. Small scale reorganisations can then encourage new ways of 'doing' an established identity if the subject counters the organisational requirements that restrict her, albeit with an "ability to act [that] depends upon the contours and limits of the given situation" [80]p.87. Identity work or self-crafting can become possible through fleeting changes, rather than a radical reconstruction of behaviours or practices. An understanding of repetition within task performance also brings scope for 'unfreezing' of collective performativity for colleagues who are used to working together, through iterative resignification of social structures, processes and conventions. Here, agency "exceeds the power by which it is enabled" [64] p.15.

\section{Discussion}

Saini et al classify drivers of overuse of services into three groups: financial incentives and service integration; 'misleading psychological tendencies and erroneous beliefs'; and 'asymmetries in power between patients and healthcare providers', which may preclude appropriate consideration of patients' preferences [81]. These drivers coalesce within normative decision making, or how people 
perceive they 'should' or 'ought to' make decisions [82]. This analysis addresses the latter two categories of these drivers of overuse, by considering dominant discourse as the condition of performativity that shapes what is taken to be 'normal' or accepted as 'a truth' [83]. Butler considers that performativity "seeks to counter a certain kind of positivism according to which we might begin with already delimited understandings" [30] p.147.

The theory of performativity has been critiqued in terms of difficulties in its empirical application (e.g. [84]). I have attempted to apply a performativity-inspired lens, to open perspectives into drivers of practices and asymmetries in power, within nursing home interactions. Nursing homes and NHS healthcare services work together at organisational, service and personal levels to determine delivery of interventions but, when assumptions about who does what are left unchallenged, practices are repeated and can lead to establishment of norms in which residents' and families 'voices may not be heard [26]. Transfer of residents between a nursing home and an emergency department has been described as occurring through "practitioners' actions [that] were fixed, repetitive and focused on organizational rather than resident needs" [73] (p.160). Reiterative, normative practices may interpellate and then regulate subject positions, with enforcement through tools such as standardised assessments and checklists that diminish tailored communication and decision-making $[45,85]$. For example, the process of care planning intends to promote patient preferences and priorities [22], yet may paradoxically reduce flexible, supportive aspects of relational care [85]. Reiterative or citational practice provides conditions for unthinking, 'automatic' courses of action, if staff do not question organisational expectations and potential constraints of professional identities [73, 86].

Medicalised risk management of 'frailty' is embedded within policy and practice but has increasingly become entangled with aspirations of enabling of autonomy, choice, person-centred care and shared decision-making. The making of decisions forms part of how identity work is 'done' and constitutes ways through which dominant power relations can become reproduced,or can potentially be disrupted. A resident's identity work relates to their being recognised as a certain kind of person through their engagement in everyday experiences [87], shaped by repetitive routines and conventions of the nursing home. Dominant discourses, the very condition of performativity, remain open to change as movement of discourse means conventional processes can be resisted and discursive meaning can be shifted, such that subjects can be constituted differently - a possibility that is central to the concept of performative resignification [88]. As illustrated in the opening vignette, an outcome other than inevitable hospitalisation would require disruption to collectively performative effects at interfaces between a nursing home, primary care, an ambulance service and an acute hospital. Achieving disruption to conventional practice then raises questions of, 'Who could bring this about? What are the conditions under which a different outcome could be realised?'. Actions involved are not those of single subjects, but rely on broad networks of social interrelations and organisational practices, through which agency is dispersed. Through everyday reiterative practices, assumptions and influences can gradually evolve if the compulsory repetitions of acts is recognised and questioned, then bringing possibilities for their disruption.

Coproductive approaches move toward the expanded definitions of what it means to be 'personcentred', through a growing recognition of the active roles that individuals can play as partners in care processes, and acknowledgement of the contribution of families and wider social supports [38]. Opportunities for collaborative practices and participation between professionals and older adults living with frailty in nursing homes allow reimagining of established conventions [89] and further extend recommendations for improvement work as a shared enterprise with nursing home staff and healthcare practitioners [23]. Alternative interpretations could draw on coproduction as a disruptive opening within established norms, through involvement of older people and family members in 
codesign of tools and services, to enhance relevance and value [90]. Inherent challenges undeniably include the complement of staff to accommodate different or more flexible ways of working, at the same time as meeting the demands of practical tasks.

\section{Conclusions}

In this article, I have considered the social world of nursing homes, characterised by "normalization, discipline and surveillance" [91] p187. A focus on a potentially avoidable transfer of an older person from a nursing home to hospital has allowed exploration of conventions, identity and agency that are situated in a normative discourse that objectifies and medicalises frailty. I have considered tensions in the assertion that "residents and their relatives must be at the centre of decisions about care" [24] p1, by drawing on Judith Butler's theory of performativity as a tool to consider repetitive practices that may go unquestioned within a risk-averse system, constituting subject positions and establishing asymmetric power relations. Through this theoretical lens, I have sought to open avenues and perspectives that move beyond deficit explanations calling for more funding, resources or health services. There is scope for research into promoting integration between discourses of frailty and those of coproductive approaches, aligning with broader calls to reset contexts of 'too much medicine'.

\section{Acknowledgements}

I am grateful to Jeremy Howick and Susanne Uusitalo for the opportunity to present an early version of this work at the 'Too Much Medicine' conference held in April 2017 at the University of Oxford, and for their encouragement to develop the paper. I am also grateful to the editor and to the anonymous reviewers for their constructive comments. 


\section{References}

1.NHS England. Next Steps on the Five Year Foward View. https://www.england.nhs.uk/wpcontent/uploads/2017/03/NEXT-STEPS-ON-THE-NHS-FIVE-YEAR-FORWARD-VIEW.pdf. Accessed 27 Feb 2018.

2. Badger F, Thomas K, Clifford C. Raising standards for elderly people dying in care homes. Eur J Palliat Care. 2007;14:238-41.

3. Imison C, Curry N, Holder H, Castle-Clarke S, Nimmons D, Appleby J, et al. Shifting the balance of care. Res Summ. 2017.

4. Malone M, Danto-Nocton E. Improving the hospital care of nursing facility residents. Ann LongTerm Care. 2004;:42-9.

5. Ahearn DJ, Jackson TB, Mcllmoyle J, Weatherburn AJ. Improving end of life care for nursing home residents: an analysis of hospital mortality and readmission rates. Postgrad Med J. 2010;86:131-5.

6. McDermott C, Coppin R, Little $P$, Leydon $G$. Hospital admissions from nursing homes: a qualitative study of GP decision making. Br J Gen Pract. 2012;62:e538-45.

7. Grabowski DC, Stewart KA, Broderick SM, Coots LA. Predictors of nursing home hospitalization: a review of the literature. Med Care Res Rev MCRR. 2008;65:3-39.

8. Humphries, Richard. Social care funding and the NHS An impending crisis? 2011.

https://www.kingsfund.org.uk/sites/default/files/field/field_publication_file/Social_care_older_peo ple_Kings_Fund_Sep_2016.pdf. Accessed 7 May 2018.

9. Brook RH, Vaiana ME. Using the Knowledge Base of Health Services Research to Redefine Health Care Systems. J Gen Intern Med. 2015;30:1547-56.

10. Shekelle P. The Appropriateness Method. Med Decis Making. 2004;24:228-31.

11. Elshaug AG, Rosenthal MB, Lavis JN, Brownlee S, Schmidt H, Nagpal S, et al. Levers for addressing medical underuse and overuse: achieving high-value health care. The Lancet. 2017;390:191-202. 
12. Wenger NS, Roth CP, Shekelle P. Introduction to the Assessing Care of Vulnerable Elders-3 Quality Indicator Measurement Set. J Am Geriatr Soc. 2007;55:S247-52.

13. Carel H, Macnaughton J. "How do you feel?": oscillating perspectives in the clinic. Lancet. 2012;379:2334-5.

14. Iliffe S, Davies SL, Gordon AL, Schneider J, Dening T, Bowman C, et al. Provision of NHS generalist and specialist services to care homes in England: review of surveys. Prim Health Care Res Amp Dev. 2016;17:122-37.

15. NHS England. NHS Five Year Forward View. 2014. https://www.england.nhs.uk/five-yearforward-view/. Accessed 2 Jan 2018.

16. Kirsebom M, Wadensten $B$, Hedström M. Communication and coordination during transition of older persons between nursing homes and hospital still in need of improvement. J Adv Nurs. 2013;69:886-895.

17. Arendts G, Popescu A, Howting D, Quine S, Howard K. 'They never talked to me about...': Perspectives on aged care resident transfer to emergency departments. Australas J Ageing. 2015;34:95-102.

18. Underwood F, Burrows L, Gegg R, Latour JM, Kent B. The meaning of confidence for older people living with frailty: a qualitative systematic review. Jbi Database Syst Rev Implement Rep.

2017;15:1316-1349.

19. Mudge AM, Banks MD, Barnett AG, Blackberry I, Graves N, Green T, et al. CHERISH (collaboration for hospitalised elders reducing the impact of stays in hospital): protocol for a multi-site improvement program to reduce geriatric syndromes in older inpatients. BMC Geriatr. 2017;17:11.

20. Kortebein $P$, Symons TB, Ferrando A, Paddon-Jones D, Ronsen O, Protas E, et al. Functional impact of 10 days of bed rest in healthy older adults. J Gerontol A Biol Sci Med Sci. 2008;63:10761081.

21. Romero-Ortuno R, O'shea D, Silke B. Predicting the in-patient outcomes of acute medical admissions from the nursing home: The experience of St James's Hospital, Dublin, 2002-2010. Geriatr Gerontol Int. 2012;12:703-713. 
22. O'Neill BJ, Dwyer T, Reid-Searl K, Parkinson L. Managing the deteriorating nursing home resident after the introduction of a hospital avoidance programme: a nursing perspective. Scand J Caring Sci. 2017;31:312-322.

23. Goodman C, Dening T, Gordon AL, Davies SL, Meyer J, Martin FC, et al. Effective health care for older people living and dying in care homes: a realist review. BMC Health Serv Res. 2016;16:269.

24. British Geriatrics Society. Unmet need, unacceptable variation and often poor quality. 2011. http://www.bgs.org.uk/fulllisting/campaigns/carehomes/carehomespressrelease.Accessed 19 Feb 2018.

25. Wong RY. Transferring nursing home residents to acute care hospital-to do or not to do, that is the question. Elsevier; 2010.

26. Laging B, Ford R, Bauer M, Nay R. A meta-synthesis of factors influencing nursing home staff decisions to transfer residents to hospital. J Adv Nurs. 2015;71:2224-36.

27. Brown AD, Coupland C. Identity Threats, Identity Work and Elite Professionals. Organ Stud. 2015;36:1315-36.

28. Butler J. Bodies that matter: On the limits of "sex." Lond Rout. 1993.

29. Butler J. Gender trouble and the subversion of identity. N Y Lond Routledge. 1990.

30. Butler J. Performative Agency. J Cult Econ. 2010;3:147-61.

31. Gowlett C. Queer (y) ing and recrafting agency: Moving away from a model of coercion versus escape. Discourse Stud Cult Polit Educ. 2014;35:405-418.

32. Foucault M. The masked philosopher. Ethics Subj Truth. 1997;:321-328.

33. Rose G. Situating knowledges: positionality, reflexivities and other tactics. Prog Hum Geogr. 1997;21:305-320. 
34. Select Committee on the Mental Capacity Act 2005. Mental Capacity Act 2005: post-legislative scrutiny. 2014. https://publications.parliament.uk/pa/ld201314/Idselect/ldmentalcap/139/139.pdf. Accessed 19 Feb 2018.

35. Rockwood K, Theou O. Frailty in Aging. Biological, Clinical and Social Implications. Introduction. Interdiscip Top Gerontol Geriatr. 2015;41:VII-X.

36. Evans EA, Perkins E, Clarke P, Haines A, Baldwin A, Whittington R. Care home manager attitudes to balancing risk and autonomy for residents with dementia. Aging Ment Health. 2018;22:261-9.

37. Munthe C, Sandman L, Cutas D. Person centred care and shared decision making: implications for ethics, public health and research. Health Care Anal.2012;20:231-249.

38. Ahmad N, Health Foundation (Great Britain). Person-centred care: from ideas to action. London: Health Foundation; 2014.

39. Pereira Gray D, White E, Russell G. Medicalisation in the UK: changing dynamics, but still ongoing. J R Soc Med. 2016;109:7-11.

40. Conrad P. Medicalization and Social Control. Annu Rev Sociol. 1992;18:209-32.

41. Hamilton RP. The concept of health: beyond normativism and naturalism. J Eval Clin Pract. 2010;16:323-9.

42. Fried LP, Tangen CM, Walston J, Newman AB, Hirsch C, Gottdiener J, et al. Frailty in Older AdultsEvidence for a Phenotype. J Gerontol Ser A. 2001;56:M146-57.

43. Manthorpe J, Iliffe S. Frailty - from bedside to buzzword? J Integr Care. 2015. doi:10.1108/JICA01-2015-0007.

44. Turner G, Clegg A. Best practice guidelines for the management of frailty. Age Ageing. 2014;43:744-7.

45. Papoutsi C, Poots A, Clements J, Wyrko Z, Offord N, Reed JE. Improving patient safety for older people in acute admissions: implementation of the Frailsafe checklist in 12 hospitals across the UK. Age Ageing. 2018;47:311-7. 
46. Gilleard C, Higgs P. Frailty, disability and old age: A re-appraisal. Health Interdiscip J Soc Study Health Illn Med. 2011;15:475-90.

47. Contino G. The Medicalization of Health and Shared Responsibility. New Bioeth. 2016;22:45-55.

48. Sturmberg JP, Bennett JM, Martin CM, Picard M. 'Multimorbidity' as the manifestation of network disturbances. J Eval Clin Pract. 2017;23:199-208.

49. Fillit H, Butler RN. The Frailty Identity Crisis. J Am Geriatr Soc. 2009;57:348-52.

50. Grenier A. The Distinction Between Being and Feeling Frail: Exploring Emotional Experiences in Health and Social Care. J Soc Work Pract. 2006;20:299-313.

51. Carel H, Kidd IJ. Epistemic injustice in healthcare: a philosophial analysis. Med Health Care Philos. 2014;17:529-540.

52. Dyrstad DN, Testad I, Aase K, Storm M. A review of the literature on patient participation in transitions of the elderly. Cogn Technol Work. 2015;17:15-34.

53. Garry A, Pearsall M. Women, Knowledge, and Reality: Explorations in Feminist Philosophy. Routledge; 2015.

54. Arendts G, Quine S, Howard K. Decision to transfer to an emergency department from residential aged care: A systematic review of qualitative research. Geriatr Gerontol Int. 2013;13:825-33.

55. Jackson AY. Performativity Identified. Qual Inq. 2004;10:673-90.

56. Weedon C. Identity and culture: narratives of difference and belonging. Maidenhead: Open University Press; 2004.

57. Fraser N. Feminist Contentions: A Philosophical Exchange. Routledge; 2013.

58. Butler J. Giving an account of oneself. Oxford University Press; 2005. 
59. Latimer J. Afterword: materialities, care, 'ordinary affects', power and politics. Sociol Health IIIn. 2018;40:379-91.

60. McGaughey J, O'halloran P, Porter S, Blackwood B. Early warning systems and rapid response to the deteriorating patient in hospital: A systematic realist review. J Adv Nurs. 2017.

61. Massey D, Chaboyer W, Anderson V. What factors influence ward nurses' recognition of and response to patient deterioration? An integrative review of the literature. Nurs Open. 2017;4:6-23.

62. Andrews T, Waterman H. Packaging: a grounded theory of how to report physiological deterioration effectively. J Adv Nurs. 2005;52:473-81.

63. Althusser L. Ideology and ideological state apparatus (Notes towards an investigation). I Lenin and philosophy and other essays (ss. 127-186). New York: Monthly Review Press; 1971.

64. Butler J. Excitable Speech: A Politics of the Performative. Psychology Press; 1997.

65. Bridges J, Nugus P. Dignity and significance in urgent care: older people's experiences. J Res Nurs. 2010;15:43-53.

66. Mulkay M, Ernst J. The Changing Profile of Social Death. Eur J Sociol. 1991;32:172.

67. Borgstrom E. Social Death. QJM Int J Med. 2017;110:5-7.

68. Department of Health. Mental Capacity Act Code of Practice. Dep Const Aff Lond TSO. 2005.

69. Dying Matters. Best Interests Decisions. Advance Care Plan. http://advancecareplan.org.uk/bestinterests-decisions/. Accessed 27 Feb 2018.

70. Birchley G, Jones K, Huxtable R, Dixon J, Kitzinger J, Clare L. Dying well with reduced agency: a scoping review and thematic synthesis of the decision-making process in dementia, traumatic brain injury and frailty. BMC Med Ethics. 2016;17:46. 
71. Prainsack B. The "We" in the "Me": Solidarity and Health Care in the Era of Personalized Medicine. Sci Technol Hum Values. 2018;43:21-44.

72. Willis K, Collyer F, Lewis S, Gabe J, Flaherty I, Calnan M. Knowledge matters: producing and using knowledge to navigate healthcare systems. Health Sociol Rev. 2016;25:202-16.

73. McCloskey R. The 'mindless' relationship between nursing homes and emergency departments: what do Bourdieu and Freire have to offer? Nurs Inq. 2011;18:154-64.

74. Richardson S, Casey M, Hider P. Following the patient journey: Older persons' experiences of emergency departments and discharge. Accid Emerg Nurs. 2007;15:134-40.

75. Culbertson C. The ethics of relationality: Judith Butler and social critique. Cont Philos Rev. 2013;46:449-63.

76. Giddens A. The constitution of society: Outline of the theory of structuration. Univ of California Press; 1986.

77. Foucault M. The Subject and Power. Crit Inq. 1982;8:777-95.

78. The Choice in End of Life Care, Programme Board. What's important to me: A Review of Choice in End of Life Care.

http://www.ncpc.org.uk/sites/default/files/CHOICE\%20REVIEW_FINAL\%20for\%20web.pdf. Accessed 26 Feb 2018.

79. Butler J. Can one lead a good life in a bad life? Adorno Prize Lecture. 2012.

80. Magnus KD. The Unaccountable Subject: Judith Butler and the Social Conditions of Intersubjective Agency. Hypatia. 2006;21:81-103.

81. Saini V, Garcia-Armesto S, Klemperer D, Paris V, Elshaug AG, Brownlee S, et al. Drivers of poor medical care. The Lancet. 2017;390:178-190.

82. Djulbegovic B, Elqayam S, Dale W. Rational decision making in medicine: Implications for overuse and underuse. J Eval Clin Pract. doi:10.1111/jep.12851. 
83. Selland MK. The edge of messy: interplays of daily storytelling and grand narratives in teacher learning. Teach Teach. 2017;23:244-61.

84. Riach K, Rumens N, Tyler M. Towards a Butlerian methodology: Undoing organizational performativity through anti-narrative research. Hum Relat. 2016;69:2069-2089.

85. Borgstrom E. Advance care planning: between tools and relational end-of-life care? BMJ Support Palliat Care. 2015;5:216-7.

86. McCloskey RM. A Qualitative Study on the Transfer of Residents Between a Nursing Home and an Emergency Department. J Am Geriatr Soc. 2011;59:717-24.

87. Gee JP. An Introduction to Discourse Analysis: Theory and Method. Routledge; 2014.

88. Youdell D. Diversity, Inequality, and a Post-structural Politics for Education. Discourse Stud Cult Polit Educ. 2006;27:33-42.

89. Mondaca M, Josephsson S, Katz A, Rosenberg L. Influencing everyday activities in a nursing home setting: A call for ethical and responsive engagement. NursInq. doi:10.1111/nin.12217.

90. Nicholson C, Gordon AL, Tinker A. Changing the way "we" view and talk about frailty.... Age Ageing. 2017;46:349-51.

91. McCloskey R, Van Den Hoonaard D. Nursing home residents in emergency departments: a Foucauldian analysis. J Adv Nurs. 2007;59:186-94. 
[1] Nursing homes in the United Kingdom are predominantly independently owned institutions where twenty-four hour nursing support is provided for people who often have several medical diagnoses, are taking multiple medications, may have limited mobility and impairment of cognition.

[2] The vignette represents events from my experience as a relative of a nursing home resident.

[3] I have used the term 'nursing home resident' for consistency through this paper though I acknowledge that this identity categorisation is problematic. 